\title{
CIÊNCIAS SOCIAIS E ÉTICA: SOBRE O RESPEITO AOS OUTROS SABERES
}

\section{SOCIAL SCIENCES AND ETHICS IN TERMS OF OTHER KNOWLEDGE: OTHER KNOWLEDGE IN SOCIAL SCIENCES AND ETHICS}

\author{
Francisca Márquez*
}

\section{Introdução}

Na América Latina, o pensamento social costuma estar imerso nas diversas formas de entender e construir o Estado, a Nação e a democracia. Historicamente, a sua principal preocupação se relaciona com a discussão dos pertencimentos nacionais e do Estado. Essa busca conceitual faz parte de um campo intelectual atravessado por polêmicas teóricas com implicações práticas e políticas. Na constituição de nossos Estados Nacionais, as conceptualizações, às vezes divergentes, estão presentes desde a ruptura colonial, atravessando a história do pensamento social e antropológico até os nossos dias. As produções brasileira, mexicana, peruana, equatoriana ou colombiana são bons exemplos desta relação crítica e aplicada da disciplina. Entretanto, os debates sobre Nação, Estado e as suas condições de viabilidade não são capítulos concluí- dos; eles permeiam a produção teórica e as preocupações atuais dos intelectuais latino -americanos.

A história das Ciências Sociais na América Latina nos mostra que não podemos falar de ciência e Nação, pesquisa e engajamento, se não assumimos que devemos entrar na complexa trama das estruturas e dos poderes. Para articular os saberes dos intelectuais ao devir de nossas sociedades, é necessário saber com que estruturas e campos de interesses sociais teremos que lidar. Mas também com que saberes, saberes outros, a ciência deverá dialogar.

A análise do desenvolvimento das Ciências Sociais na América Latina demonstra que durante as décadas de 1930 - 1970 a institucionalização e a consolidação foram as principais características desse campo do saber (FLORANI, 2015; LANDER, 2000; CALDERÓN, 1987, entre outros). A partir da segunda década de 1950, a institucio-

\footnotetext{
* Antropóloga e Docente da Universidade do Chile (Santiago/Chile). E-mail: fmarquezb@gmail.com
} 
nalização das Ciências Sociais foi mais intensa, e se caracterizou pelo aumento da matrícula estudantil, pela criação de novas carreiras e pela fundação de novos centros de pesquisa, revistas e redes internacionais. O conhecimento será assim assumido como um fator estratégico para o funcionamento do Estado, sendo a universidade uma das principais, e, às vezes, a única fonte autorizada para a geração de conhecimento técnico-científico (GRACIARENA, 1970).

Esta centralidade que a universidade adquire na conformação do saber em parte se explica por fatores estruturais, como a inserção das economias latino-americanas no novo mercado mundial, pelas políticas de substituição de importações, e também pela emergência de novos grupos ascendentes. Entretanto, junto a esse processo de consolidação do mundo intelectual, nascem, tanto dos estudantes quanto dos docentes, demandas para a transformação da estrutura universitária tradicional.

A conjuntura histórica gerada a partir da revolução cubana e da condição política latino-americana foram fatores detonantes para o questionamento dos saberes produzidos nas salas de aula universitárias. A adoção do marxismo como fonte teórica por parte das novas gerações de científicos sociais latino-americanos abrirá o debate a uma ciência crítica e de validação da práxis como fonte de conhecimento para a ação. Surge, então,a figura do intelectual comprometido com a transformação social: Orlando Fals Borda, Eliseo Verón, José Nun, Fernando H. Cardoso, Enzo Faleto, Anibal Quijano, Marta Harnecker, Samir Amin, Luis Razeto, entre outros. Todos eles conduzirão o debate das Ciências Sociais a posturas críticas e de compromisso com as transformações das sociedades latino-americanas.
Entre as décadas de 60 e 70, a crise e a instabilidade política afetarão a maioria dos países da região com golpes militares que desmantelarão e reprimirão a institucionalidade universitária, especialmente nas faculdades de Ciências Sociais. 0 Brasil é o único país onde as Ciências Sociais continuarão desenvolvendo-se apesar do regime militar. Nos demais países, as Ciências Sociais, cientistas, professores e estudantes são submetidos à perseguição política (CALDERÓN, 1987; ANDRADE, 1990). $\mathrm{Na}$ Argentina, as Ciências Sociais perdem autonomia e são declaradas politicamente ilegítimas. No Chile, a censura e o desmantelamento das universidades públicas e, particularmente, das faculdades de Ciências Sociais, serão reforçados pela expulsão e exílio de seus acadêmicos. Apesar disso, o desenvolvimento das Ciências Sociais não se deteve, muito pelo contrário. Durante as ditaduras, algumas delas se fortaleceram e conseguiram descobrir caminhos alternativos de conhecimento e alianças com grupos sociais para subverter a repressão militar. Nasce, assim, um setor acadêmico independente das salas de aula universitárias que, graças à cooperação internacional, cria novos centros acadêmicos e organizações orientadas à investigação-ação e ao compromisso político para a ação social popular (BRUNNER, 1987, p. 11).

Uma vez recuperadas as democracias em países como Argentina, Brasil, Uruguai e Chile, o processo de reinstitucionalização permitiu que as universidades reabrissem carreiras e centros de pesquisa em Ciências Sociais que tinham sido fechados durante as ditaduras. No caso do Chile, entretanto, a Universidade do Chile foi fortemente desmantelada e desmembrada, não podendo recuperar jamais as suas redes regionais. A 
abertura democrática e a reinstitucionalização das Ciências Sociais na América Latina, sem dúvida, favoreceram a recuperação do papel das universidades no desenvolvimento das Ciências Sociais.

Entretanto, veremos a partir dos anos 90 que progressivamente os apoios governamentais são condicionados às áreas de conhecimento mais técnicas e funcionais a um modelo econômico neoliberal e global. De fato, o desenvolvimento institucional e intelectual das Ciências Sociais será orientado e tensionado pelas características do modelo de desenvolvimento econômico, situação que vulnera a institucionalização da investigação e as suas possibilidades de desenvolvimento (ANDRADE, 1990).

Sem intenção de criar generalizações para toda a América Latina, este artigo analisa o caso das Ciências Sociais no Chile, através do qual veremos como a forte dependência ao modelo econômico neoliberal tende a tencionar e a postergar o exercício teórico e metodológico crítico e comprometido com a transformação social.

\section{As Ciências Sociais no Chile}

No caso específico do desenvolvimento das Ciências Sociais no Chile, a sua aparição e participação nos debates latino-americanos é tardia. Isto se explica, em parte, pela tendência intelectual e política de observar e apresentar a homogeneidade da população chilena como uma virtude da nossa Nação. Distante dos críticos e complexos debates de países como México, Peru ou Brasil, as Ciências Sociais chilenas nascem no começo do século XX com uma forte marca evolucionista, estabelecendo um certo menosprezo pelas sociedades pré -hispânicas, pelo indígena, pelo mestiço, e pelas suas culturas e saberes. Daí o caráter conservador e folclorizante das origens das Ciências Sociais em geral no nosso país. Apesar dos esforços pioneiros de alguns cientistas sociais, especialmente dos antropólogos, para resgatar os fragmentos das culturas originárias, será apenas no final dos anos cinquenta que os estudos sobre as culturas pré-hispânicas se iniciam sob uma ótica distinta. As ideias do indigenismo mexicano, por exemplo, chegam tardiamente no Chile. Será somente em meados da década de sessenta que as Ciências Sociais conseguirão abrir-se a novos campos e objetos de estudo.

0 marco da reforma universitária que parte desde a Universidade Católica do Chile (1967-1973) terá como consequência crítica a importância que adquirirão os problemas de poder universitário. As grandes ideias-força da reforma abrirão o mundo acadêmico a uma universidade crítica, comprometida, pluralista e democrática em seus saberes, como também na sua gestão e poder de decisão. 0 caráter da Universidade Católica mudará radicalmente com a reforma, mas com o golpe e a intervenção militar, essa mesma reforma será revertida, levando inclusive à ruptura do movimento estudantil reformista. A fragilidade e reversibilidade dos processos universitários é evidente (GARRETÓN, 2018).

Nesse período, se houve qualquer construção inicial de uma ciência social crítica no interior das universidades chilenas, isso termina abruptamente com o golpe de 1973. Certamente, a ditadura não fez mais que aprofundar a distância entre as preocupações das Ciências Sociais nas universidades e os problemas nacionais. Durante os 17 anos de ditadura, o pensamento crítico não teve lugar no interior destas instituições, senão que foi relegado a fundações e organizações não governamentais. Duran- 
te esses anos de forte repressão e censura, o saber das Ciências Sociais pôde participar nos processos de resistência através de marcos conceituais e metodológicos inspirados nos princípios da investigação-ação.

A ênfase em modelos analíticos focados nos movimentos sociais atraiu intelectuais do mundo todo. Uma pesquisa significativa foi a "intervenção sociológica”, método tourainiano de estudo dos movimentos sociais, realizada com o movimento de moradores chileno - movimiento de pobladores chileno - entre 1985 e 1986 em Santiago. 0 livro " Moradores: luchas sociais e democracia no Chile" - "Pobladores: luchas sociales y democracia en Chile” -, obra originalmente publicada em francês (1989) pela editora L'Harmattan, apresenta os resultados desta pesquisa realizada em plena ditadura e financiada pelo Ministério Francês de Assuntos Estrangeiros, graças à intermediação de Alain Touraine. Foram anos de debate e construção de sólidos corpus teóricos sobre os movimentos de moradores, os "sem teto" e o comitê de desempregados; análise que também alimentaria ações concretas de resistência para a recuperação da democracia.

A fins de 1989, uma vez terminada a ditadura, muitos destes intelectuais e cientistas sociais passaram a ser parte do novo projeto governamental de transição à democracia. Era necessário reconstruir o Estado. As fundações e organismos governamentais perderam paulatinamente os seus intelectuais, assim como os financiamentos de cooperação internacional. Recuperada a institucionalização universitária, entre- tanto, nem os acadêmicos, nem os marcos teórico-conceituais críticos passaram a fazer parte do pensamento e labor universitário. Muito pelo contrário, as universidades foram progressivamente repensadas e reorganizadas em função de indicadores de qualidade internacional, buscando estar ao dia com os padrões de produtividade que vinham fundamentalmente dos Estados Unidos.

A escassez de acadêmicos com títulos de pós-graduação tornou urgente a criação de uma política de bolsas para o estrangeiro. Com isso, novos modelos de pensamento e de referentes teóricos começaram a ser importados, principalmente desde os países anglo-saxões. A incipiente tradição de pensamento crítico que as universidades haviam alcançado implementar desde os anos 60 e posteriormente as fundações e ONGs durante os anos 70 e 80 foi removida e anulada.

Atualmente, apesar da proliferação de universidades, de cientistas sociais e de f1nanciamentos para pesquisas no campo social, este debate ainda está em construção. Entre os desafios que limitam o livre pensamento ao interior das Ciências Sociais nas universidades podemos mencionar:

a) 0 forte apreço e ponderação que têm as universidades anglo-saxônicas, europeias e norte-americanas sobre as universidades latino-americanas para a concessão de bolsas do governo do Chile para estudos de pós-graduação. No ranking da CONICYT $^{1}$ para a concessão de bolsas de pós-graduação em Ciências Sociais, não aparece nenhuma 
universidade latino-americana (CONICYT, 2017). Assim, as possibilidades de estudar uma pós-graduação na América Latina, financiada pelo Estado do Chile, se reduzem. As implicações em termos de construção de diálogos de saberes do Sul ou entre intelectuais latino-americanos são claras. 0 desincentivo a estudar Ciências Sociais em universidades latino-americanas é também um desincentivo a construir e aprofundar na consolidação de corpus conceituais e metodológicos enraizados em saberes próprios.

b) A avaliação da produtividade acadêmica centrada quase única e exclusivamente em publicações em revistas indexadas WoS e SCOPUS, na sua maioria de fala inglesa. Das 3.097 revistas de Ciências Sociais indexadas em WoS, segundo o nível de impacto, aproximadamente 3\% estão em espanhol ou português. No Chile, publicar se tornou obrigatório entre os acadêmicos universitários: "publish o perish". A competição gerada por estas publicações tem levado a que muitas universidades paguem aos seus acadêmicos aproximadamente 1.500 dólares por publicação indexada. Reduzir a produtividade intelectual a publicações indexadas, na sua maioria em inglês, incentiva que o trabalho universitário se feche em si mesmo e evite o entorno e os saberes que estão para além das estreitas aulas universitárias ${ }^{2}$. c) A grande dependência ao mercado (imobiliário, de saúde, urbano e de transporte, de meio ambiente, entre outros) para o patrocínio de infraestrutura universitária e pesquisa é uma evidencia até nas universidades públicas, como a Universidade do Chile. Um bom exemplo é a Faculdade de Economia desta casa de estudos, cuja biblioteca central herda o nome de Andrónico Lucsic, um dos empresários mais milionários do Chile. Na Pontifícia Universidade Católica (PUC), Anacleto Angelini, um poderoso empresário do setor florestal e pesqueiro, financia o Centro de Inovação UC da mencionada instituição. A presença e influência de poderosos empresários na construção do conhecimento nas Ciências Sociais é indiscutível. A naturalização da relação mundo acadêmico-mundo empresarial chega a tal ponto que nas boas vindas realizada aos novos professores da PUC, o reitor da instituição recomenda trabalhar por essa aliança, sendo tarefa dos acadêmicos atrair novos capitais à casa de estudo (Discurso de boas vindas do reitor Pedro Pablo Rosso, 2010).

d) A dificuldade do Estado e dos grêmios profissionais para regular e impor princípios éticos no exercício da profissão é uma característica herdada dos tempos de ditadura. No ano de 1980, a ditadura alterou as atribuições dos Conselhos Profissionais no acompanhamen-

2. 0 acesso a benefícios de gratuidade na educação superior está condicionado à obtenção de 4 anos de acreditação por parte da Comissão Nacional de Acreditação - CNA. Isso implica, para as universidades, uma forte sujeição aos padrões de qualidade definidos pelo Ministério de Educação. A gratuidade na educação superior só beneficia cerca de 25\% dos estudantes de graduação. A grande maioria dos estudantes universitários deve se endividar para estudar. 
to do exercício da profissão, com isso, os conselhos foram limitados nas suas faculdades fiscalizadoras e normativas. Em um modelo econômico regulado pelo mercado, a ausência dos conselhos teve consequências complexas em termos de regulação ética do exercício professional. No caso da legislação ambiental $^{3}$, por exemplo, são as empresas as responsáveis em solicitar os estudos de impacto ambiental e fazer os relatórios que serão destinados aos organismos públicos correspondentes. Sabemos, entretanto, que as empresas não hesitam em vulnerar e transgredir os princípios éticos básicos, tergiversando a informação dos cientistas sociais, podendo, inclusive, mudar as suas recomendações. Inumeráveis são os exemplos de denúncia de profissionais à Procuradoria Geral da República (Colégio de Antropólogos, 2006), situação que acabou prejudicando inúmeras localidades rurais afetadas pela instalação de centrais hidroelétricas, represas, mineiras ou indústrias de cultivo e exploração marinha. A impunidade com que atuam os grandes consórcios mineiros, florestais e pesqueiros diante da legislação e da normativa é uma evidencia indiscutivel nos dias de hoje. 0 poder de intelectuais e acadêmicos das Ciências Sociais para validar a sua voz e os seus saberes em prol da defesa de localidades e comunidades é escassa. A grande quantidade de dinheiro oferecida por essas empresas a jovens cientistas sociais certamente contribuiu para a sedução de muitos deles por esse tipo de trabalho. No caso do grêmio dos arqueólogos, a situação é tão crítica que as altas compensações econômicas oferecidas pelas empresas para os estudos de impacto meio ambiental acabaram incentivando o desenvolvimento de trajetórias de pesquisadores e científicos.

\section{Os outros saberes}

No Chile e na América Latina, até hoje, o resguardo institucional do saber legítimo se exerce circunscrevendo seus objetos e métodos à ordem das disciplinas segundo a especialização do conhecimento científico. É esta compartimentação disciplinar que dá forma ao desenho institucional das universidades e seus desenhos curriculares e investigativos. Paradoxalmente, as universidades, os centros de pensamento e o saber científico parecem ter ficado defasados e alheios às desarticulações e fragmentações do pensamento moderno que rompem com a ilusão de totalidade e universalidade do conhecimento (RICHARDS, 1995). As universidades de hoje permanecem igualmente alheias às evidências socioculturais que indicam que as fronteiras do saber se estenderam para além das salas de aula, e que estes saberes também exigem ter voz. É o

3 Os projetos que se submetem ao Serviço de Avaliação de Impacto Ambiental - SEIA - são aqueles que apresentam as seguintes situações: risco para a saúde da população; efeitos adversos para os recursos naturais renováveis; reassentamento de comunidades humanas ou alteração da vida e costumes dos grupos humanos; localização em ou próxima a comunidades, recursos e áreas protegidas; alteração do valor paisagístico ou turístico de uma zona; alteração de monumentos, sítios com valor antropológico e patrimônio cultural. http://www.sea.gob.cl/evaluacion-ambiental. 
caso dos movimentos sociais indígenas em nossos países, dos movimentos estudantis, dos movimentos dos indignados, dos movimentos de moradores que exigem proteção ambiental, etc. Em todos estes há saberes outros, que exigem o direito a um lugar na construção do conhecimento e na tomada de decisões.

Entretanto, o mundo das universidades no Chile parece resistir a tais evidências, e ainda exerce a sua autoridade institucional marcando a distinção entre os saberes legítimos, autorizados, e os saberes ilegítimos. Enquanto os primeiros se encerram no marco das especializações disciplinares, as falas outras ainda transitam fora das salas e muros universitários, anunciando o desconcerto e a desordem sobre os saberes científicos (RICHARDS, 1995). Durante os anos da ditadura chilena, ressaltávamos, esta divisão entre saberes autorizados e saberes proibidos foi radical.

Tal foi a intervenção militar nas universidades e no seu labor, que, hoje, umas das discussões mais recorrentes diz respeito à autonomia do seu saber. Os postulados mais radicais advertem que a universidade e o seu labor não alcançarão nunca a autonomia se não persistirem na vocação pública. Daí a suspeita de que as universidades privadas possam alcançar dita autonomia. Porque ainda que uma universidade privada (que possui um dono) possa ser pública, jamais será da mesma forma que as estatais. A autonomia universitária é possível nas universidades estatais porque estão excluídas do âmbito da propriedade privada e pertencem a todos nós. Nas universidades privadas a autonomia poderia existir, desde que condicionada a uma forma de governo não proprietária e a um estatuto do acadêmico que assegure a sua liberdade. Entretanto, a relação entre o público e o estatal está hoje fragmentada, não tanto pela existência de universidades públicas não estatais, mas sim pelo fato de que hoje as entidades estatais devem atuar como se fossem privadas. Esse é o legado de décadas de neoliberalismo: a privatização do Estado, que é a consumação da negação do público e do conhecimento como bem comum (ATRIA, 2018).

As universidades em contextos neoliberais podem ser muito vulneráveis diante dos poderes do mercado e do Estado. Sendo uma construção social, a autonomia universitária não está nunca garantida. A sua institucionalidade e labor na construção do conhecimento se realiza com os atores e os vínculos que ao longo da história a determinam e a condicionam. A história nos mostra que o desejo por cultivar com liberdade o saber e o conhecimento não pode ignorar os interesses do império e do vaticano (SILVA, 2018).

Os projetos universitários, sendo projetos intelectuais, estão sempre histórica, política e socialmente situados. Daí a importância de explicitar essas condicionantes, pois é evidente que, pelo menos no Chile, muitas universidades não conseguem - nesse flerte condicionante com o mercado - assumir a sua função de espaço cultural, lugar de pensamento crítico e liberdade acadêmica. Muitas dessas instituições, deixam, assim, de cultivar o saber como bem público para ser transmitido às futuras gerações (STUVEN, 2018). Tanto a presença do mercado, quanto a do conservadorismo católico, parecem ser problemáticas ao interior das universidades chilenas. Duas consequências dessas determinantes são reconhecidas no trabalho das universidades chilenas: o sectarismo, que invoca a um privilégio epistemológico que perturba a atividade das relações na sociedade e nas 
mesmas universidades; e a irrelevância, que consiste no desentendimento da possível influência da fé ou da ideologia do mercado na epistemologia das ciências. Umas e outras se protegem assim nas suas "torres de marfim” (COSTADOAT, 2018).

As universidades perdem, então, o seu papel de atividade comunitária de interpretação (LARRAÍN e LIRA, 2019). E o risco se torna então a perda da liberdade para questionar e estudar com um acerta vocação pela crise e pela crítica. Nesse sentido, nas universidades cooptadas pelo mercado e pela fé, não só é arriscada a ideia de uma liberdade acadêmica para docentes e uma liberdade estudantil para os estudantes; senão também se trata, ainda e principalmente, do risco à renúncia a uma liberdade para que a pergunta - o imprevisível - ocorra. A universidade se debilita assim na sua vocação de lugar no qual nada está resguardado de ser questionado (Garrido e Pinto, 2018).

Também é complexo que estes fortes determinantes do mercado acadêmico - na maioria das vezes impostos desde os países anglo-saxônicos - debilitem a condição analítica latino-americana. Não há dúvidas que na América Latina o pensamento social - assim como a possibilidade de autonomia do nosso fazer universitário - se encontra imerso nas diversas formas de entender e construir o Estado, a Nação e a democracia. Historicamente, a função das universidades se relaciona com a discussão dos pertencimentos nacionais. Essa procura conceitual faz parte de um campo intelectual atravessado por polêmicas teóricas com implicações práticas e políticas. Na constituição dos nossos Estados nacionais, essas conceptualizações, às vezes divergentes, estão presentes desde a ruptura colonial, e o consequente processo de evangelização, até os dias de hoje.
Os debates sobre a Nação, o Estado e as suas condições de viabilidade nas nossas universidades não são capítulos concluídos; eles atravessam a produção teórica e o fazer dos intelectuais latino-americanos. Não podemos, assim, negar que a autonomia do conhecimento intelectual e universitário - sejam de propriedade do Estado ou das corporações transnacionais - está também limitada a condições culturais e geopolíticas.

Finalmente, nesta discussão sobre a autonomia, é relevante destacar o fato de que o resguardo institucional do saber legítimo se exerce restringindo objetos e métodos não de todas, mas de certas disciplinas, segundo a especialização do conhecimento científıco. É esta compartimentalização disciplinar que dá forma e desenho institucional às universidades e aos seus desenhos curriculares e de pesquisa, em prol da tão desejada autonomia. Entretanto, a especialização disciplinar, geralmente, não define um excesso de saber, senão uma renúncia consciente e voluntária ao saber dos "outros"; transformando assim a "autonomia" em uma autonomia entre parênteses (Coccia, 2017).

0 respeito temeroso e escrupuloso aos outros saberes é uma boa expressão de um tabu cognitivo. 0 confınamento em nossas aulas disciplinares, não é senão, a consideração de todo conhecimento que não provenha do mesmo objeto e do mesmo método cientificamente verificado, como um conhecimento impuro. Essa limitação epistemológica corresponde a uma limitação sociológica e historicamente situada; assim que o nascimento da universidade, mais que o nascimento de novos saberes ou conhecimentos, geralmente, nada mais é que a formação de uma organização corporativa de sábios/as em comunidades juri- 
dicamente fechadas.

0 que chamamos de disciplinas ou de ciências (no plural) não são senão as sombras das corporações universitárias. Mas o problema é que as coisas e as ideias se misturam umas com as outras sem se preocupar pelos interditos ou as etiquetas; circulam livremente sem esperar autorização; se estruturam de acordo a formas e forças insuspeitas pelo corpo social dos e das docentes. É bem certo que é o reconhecimento desta faceta da autonomia o que possibilita a chamada filosofia: um vínculo entre as ideias e o conhecimento que não está mediatizado por nenhuma disciplina ou norma, porque o mundo é o espaço onde as coisas e as ideias estão misturadas de maneira heterogênea, caótica e imprevisível. Se os conhecimentos que a universidade produz pretendem tornar-se mundanos, conhecimentos e saberes deste mundo deverão respeitar que, no mundo, nada está ontologicamente separado do resto.

Sabemos, entretanto, que as experiências do conhecimento sempre implicam o enfrentamento entre saberes: os saberes das disciplinas, dos arquivos, da escrita científica - tradicionalmente encerrados nas bibliotecas e salas universitárias - e os saberes que nascem das práticas concretas, cotidianas, rituais e corporificadas, que circulam mais além ou mais próximos destes lugares. 0 que poderíamos aprender da observação e escuta destas práticas, oralidades, cotidianidades e atos performáticos? Que tensões poderiam nos mostrar que não tenham sido reconhecidas por saberes fundamentados em textos e documentos cientificamente legitimados? A complexa relação entre memória, oralidade e arquivos em contextos de dominação e repressão em nosso continente, fazem, destas, perguntas de extrema relevância para o questionamento do saber acadêmico universitário hoje. Se partimos da premissa de que os documentos e arquivos acadêmicos - inclusive aqueles que estão legitimados pelos processos de indexação internacional - oferecem limites importantes na busca da compreensão de nossas culturas e seus saberes diversos, deveríamos nos perguntar então quais seriam estas histórias, memórias e saberes que se fariam visiveis.

Sem dúvida, todo ato cotidiano, todo ato ritual, toda prática corporificada e performática contém, por definição, um conhecimento. No efêmero de um baile; nos editos reais que se queimam e se movem ao ritmo do kultrún ${ }^{4}$; nos corpos desnudos de Lemebel e Casas sobre a égua branca ${ }^{5}$; nos corpos empoeirados das pobladoras de ANDHA - Chile ${ }^{6}$, que mergulham desesperados nos espelhos d'água do Palácio de La Moneda e trepam por suas grades; nos corpos dos travestis ostentando seu orgulho gay em frente a La Moneda; dos ovários de

4. Tambor cerimonial utilizado pelos/as machi (xamãs) do povo indígena mapuche. N. da T.

5. A autora faz referência à performance "Refundación de la Universidad de Chile", de 1988, na qual os performers Pedro Lemebel e Francisco Casas, dupla de artistas denominado Yeguas del Apocalipsis, ingressaram no campus Juan Gómez Millas da Universidad de Chile,junto às poetas Carmen Berenguer, Carolina Jerez e Nadia Prado, montados nus sobre uma égua, durante uma ocupação da universidade realizada em plena ditadura militar chilena. (Fonte: www.yeguasdelapocalipsis.cl). N. da T.

6 Asociación Nacional de Deudores y Deudoras Habitacionales. N. da T. 
papelão cobertos de rosários sobre o portal da Catedral, invocando o direito ao aborto... Em todos estes gestos corporalizados há um saber, um grito e um gesto político que, como tal, contribui à sua legitimação e visibilidade.

Se se admite que através das práticas cotidianas, rituais ou performáticas se transmite conhecimentos vitais, é porque nelas há também memórias, tradições e demandas pelo próprio lugar na história do conhecimento. 0 conhecimento, tal como a cultura, não é algo que possa permanecer petrificado no papel ou na escrita. É arena de disputa social. Em cada baile e movimento do corpo se estabelecem reivindicações de agência cultural. Todos estamos em cena, nós todos, os atores, participamos simultaneamente e entrelaçados neste drama, ainda que não tenhamos a capacidade de escrita, ou que inclusive tenhamos perdido a capacidade de fala. Porque nelas, a "agência cultural" não é individual, mas coletiva; coletivos são cada um dos movimentos, dos ritmos, das ações de representação. É esta condição que outorga marca epistemológica e política a todo ato cotidiano, rotineiro, ritual e de performance.

Se a escrita deslocou e deslegitimou outros sistemas epistemológicos e mnemônicos, com as práticas corporalizadas e não verbais eles recuperam o seu lugar como formas válidas de conhecimento. As práticas corporalizadas estão e existem enquanto estão aí, atos efêmeros e não reprodutíveis, e por isso tão dificilmente reprimíveis. As Yeguas del Apocalipsis nos ensinam que a Universidad de Chile, historicamente masculina, não poderia senão ser reinventada desde este gesto de subversão que supõe a condição homossexual em uma casa de estudos que se erige misógina por definição. $\mathrm{Ou}$ as mulheres pobladoras de Andha
Chile, para quem a fala, e o papel, assim como os trâmites burocráticos, já não têm lugar, somente o corpo dolorido, cansado, empoeirado dos sem casa como única evidência e ponta de lança.

0 fascinante é que, mesmo desenvolvendo-se nos espaços públicos, cada um destes saberes, ações e movimentos permitem uma agência e nos conduzem a significados que, para se revelarem, requerem a nossa presença. A ação e o conhecimento ali desdobrados se transformam em coletivos, uma vez que são públicos e abertos. Movimentos e saberes que não necessariamente gozam de fácil tradutibilidade, pelo que podem permanecer enigmáticos e indecifráveis à cultura da linguagem de arquivo, letrada e científica. As implicações políticas destes gestos enquanto saberes corporalizados, vivos, intangíveis e heterotópicos falam de saberes outros que não correspondem ao arquivo letrado, um arquivo que nega e proíbe as vozes subalternas. As práticas do corpo vêm, então, desorganizar as categorias e a ordem cientificista, a subvertê-la e a romper os marcos sociais da memória e o conhecimento disciplinar.

\section{Considerações finais}

Qual é o requisito para que este diálogo se construa? Certamente o primeiro passo é romper com a violência simbólica da comunicação entre saberes que se ignoram. Não se trata de uma simples interdisciplinaridade, mas de construir conjuntamente saberes, objetos, sujeitos, situações e campos de realidade ainda desconhecidos por uns e outros. Pensar o modo como o saber universitário possa hoje conectar-se com a sociedade, com a diversidade, passa pela pergunta por atravessar os limites de seu saber, multiplicando os vínculos com os 
saberes locais e em movimento. A defesa desta heterogeneidade de saberes oblíquos supõe um novo modelo de conhecimento, capaz de interrogar as suas próprias convenções discursivas e cientificistas. A experiência e a prática encarnada nos corpos e cotidianidades adquirem, assim, valor como construção epistemológica. Daí a possibilidade de abrir espaços a formas de saberes situados, coletivos e descentralizados. Para tanto, certamente é necessário revisar os protocolos do discurso naturalizado da coerência científıca e positivista.

Historicamente, a ciência foi pensada através da defınição de problemas aplicados à resolução de perguntas que preocupam a sociedade. É a diferença entre uma ciência básica e uma ciência aplicada, sendo a primeira a base da construção de saberes que logo terão o seu alcance aplicado. Mas a ciência comprometida é algo que certamente não esteve presente da mesma maneira e não goza de legitimidade no interior das salas de aula universitárias. Tradicionalmente, existiu colaboração entre as universidades e as comunidades nas pesquisas de base, na ajuda na formação de comunidades, na busca de recursos para a ação sociopolítica. Entretanto, a pergunta hoje é: como avançar a uma universidade comprometida com a comunidade e os seus saberes? Como fortalecer estes laços, não só unilateralmente, mas que sejam laços de mútua reciprocidade na perspectiva de uma coprodução de conhecimento? Porque nem toda ciência aplicada goza do compromisso como coprodutora de conhecimento, deste diálogo em igualdade de condições.

Perguntar-se pela relação entre ciência e entorno é um tema complexo por várias razões. A primeira é que a pergunta pelo saber e pela axiologia da ciência nasce justamente quando esta observa as con- sequências (às vezes nefastas) de sua produção de conhecimento. A questão ética e de questionamento a seus próprios saberes adquire toda sua força quando os estragos sobre as comunidades estudadas começam a ser observados. A segunda complexidade desta pergunta reside no fato que nos obriga a reler e revisar o fazer científico em sua totalidade e não somente em seus resultados. Ou seja, o questionamento e a resposta aos problemas gerados pela pesquisa científica necessitam incorporar a análise do processo de pesquisa completo. E é justamente aí onde os pressupostos de objetividade da ciência tendem a desmantelar-se ante a evidência de que os critérios do saber, assim como os critérios éticos, podem ser bem distintos segundo os contextos de onde se originam.

A diversidade de contextos de produção de saberes deixa em evidência também que o ethos do cientista social sempre terá que deparar-se com outros ethos e outras éticas. Uma axiologia da ciência social por essência deverá saber dialogar com essas outras axiologias de saberes e "fazeres". Neste sentido, se requer do fazer científico e em especial das Ciências Sociais, mais que verdades, mas perspectivas para compreender as formas com as quais temos estruturado nossos conhecimentos e como estes alteram a nossa convivência (Hirsch, 2004; Roig, 2007). Reivindicar a responsabilidade da ciência é assumir este desafıo ético do respeito às muitas verdades. A verdade ou as verdades são patrimônio de todos os seres humanos; compatibilizar o rigor científico com a transparência e a responsabilidade ética com tais verdades é um desafio. Assim como existem obrigações com a disciplina, estas convivem e se sobrepõem às obrigações com a sociedade e com a cultura, com a espécie humana, com outras espécies e 
com o meio ambiente. Para as Ciências Sociais em seu conjunto, isto é especialmente revelador, uma vez que o seu objeto de estudo são justamente as sociedades, e o método obriga a desenvolver relações próximas com pessoas (AAA, 1998: 3).

Neste campo de compromissos e interesses, é inevitável que surjam conflitos. A discussão ética parte da premissa de que a geração e o uso apropriado do conhecimento das comunidades e desde estas, possui como fim o resguardo e respeito às culturas. Mas também se reconhece que a geração do conhecimento social é um processo que se vale de perspectivas diferentes e em constante mutação. São estas premissas que, por razões morais e práticas, tornam relevante que a geração e utilização deste conhecimento devam ser obtidas atendendo a considerações éticas (AAA, 1998: 4).

0 desenvolvimento de relações de convivência no trabalho de campo certamente exige aderir ao consentimento informado e aberto. Mas, acima de tudo, exige que o pesquisador seja capaz de "objetivar a sua participação" ou presença no lugar (Bourdieu, 2003: 43). Esclarecer os próprios interesses e buscas no interior da comunidade estudada é a principal exigência para uma pesquisa social eticamente responsável. Construir os limites da relação é um trabalho de todos, mas criar as condições para que isto seja factível é responsabilidade do cientista social.

Nas ciências antropológicas, o esfacelamento da observação participante como garantia de "imersão" compreensiva e respeitosa com a alteridade instala a pergunta pela ética junto à pergunta pela objetivação dessa participação no lugar. É Bourdieu, sociólogo, quem instaura a dúvida a respeito da ilusão da empatia com o nativo como garantia de compreensão e respeito a essa alteridade (BOURDIEU e WACQUANT, 1992; BOURDIEU, 1999; BOURDIEU, 2003).

Para as Ciências Sociais, o problema é especialmente complexo: em um mundo letrado, a quebra da autoridade etnográfica relaciona-se com o questionamento à superioridade do conflito na interpretação e compreensão da realidade social. Se a etnografia produz interpretações culturais a partir da experiência em terreno, como esta experiência, não sujeita a regras, transforma-se em informe escrito autorizado?

Certamente, nem a experiência nem a atividade interpretativa do pesquisador podem ser considerados inocentes. A pesquisa social, mais que a interpretação de "outra" realidade, é sempre uma negociação construtiva que envolve a dois ou mais sujeitos. Não há significado discursivo sem interlocução e contexto. Uma forma de representar esta complexidade discursiva é compreender o curso geral da pesquisa como uma negociação contínua (BOURDIEU, 1999).

Atualmente, parece indispensável insistir na necessidade de explicitar as intenções e os procedimentos que são postos em prática nas pesquisas sociais. Nos termos de Bourdieu, de explicitar e objetivar a própria participação na pesquisa e na comunidade envolvida. Seja qual for o objetivo da pesquisa, esta sempre implica uma relação social que gera efeitos sobre os resultados obtidos. Para Bourdieu, somente a reflexividade, que é sinônimo de método - mas uma reflexividade reflexiva, fundamentada em um ofício - permite perceber e controlar, à medida em que avança a pesquisa, os efeitos do contexto e da interação.

0 sonho positivista de uma perfeita inocência epistemológica, nos adverte Bourdieu, oculta o fato de que a diferença não está entre a ciência que efetua uma construção e a que não o faz, mas entre a que o 
faz sem saber e a que, sabendo-o, se esforça por conhecer e dominar de forma mais completa os atos e os efeitos que estes produzem. A objetivação é uma exigência ética do pesquisador e supõe, nestes termos, analisar as condições sociais de possibilidade de tal experiência de pesquisa. Do mesmo modo, implica analisar a postura adotada na situação de pesquisa dando conta tanto de seus interesses como de sua filiação disciplinar. Nestes termos, construir uma ética das Ciências Sociais exige partir da base de uma ontologia que se nega a separar e a opor objeto e sujeito.

Se antes não havia dúvida para as Ciências Sociais de que em sua etapa de fundação era o cientista, frequentemente a serviço de interesses colonialistas, quem definia essa verdade e essa autoridade, atualmente tal "autoridade científica" não se sustenta nem se legitima em termos epistêmicos e axiológicos se não se vincula a uma verdade compartilhada, polifônica e enraizada em um perspectivismo. Neste aspecto, os resultados da pesquisa e do conhecimento científico pertencem a todos, logo, os cientistas sociais são responsáveis pública e politicamente pelo conhecimento gerado.

Como descrever e respeitar eticamente as diferenças e as formas culturais que competem para serem representadas neste tempo e espaço que é a cultura nacional? A pergunta pela gênese de novas configurações culturais, identitárias e de soberanias nos novos espaços transnacionais e globalizados reinstala a pergunta pelo compromisso ético com atores que se movem de uma cultura a outra. As ciências da sociedade parecem precisar compreender a multilocalidade e a polifonia como recursos na construção de soberanias que se formam no movimento e na transgressão à mirada única.
Este princípio metodológico toma sempre a forma dialógica, ao ponto que às vezes não saberemos bem quem é o entrevistado e quem é o entrevistador. Trata-se então de submeter a posição do observador à mesma análise crítica a que submetemos o objeto que pretendemos construir. Desde um ponto de vista metodológico, a única maneira de começar a fazer perguntas pessoais provocativas e ter a expectativa de embarcar em conversas substanciais sobre a complexa experiência de marginalização extrema, nos diz Bourgois, consiste em entabular relações duradouras baseadas no respeito mútuo.

Partindo desta premissa, segue uma segunda consequência, a saber, o caráter profundamente político do trabalho e do saber social. Efetivamente, não há campo científico, por puro que seja, que não contenha uma dimensão política; tampouco há campo ou jogo político possível que não se pergunte pela verdade de seus postulados.

0 desafio de uma representação eticamente responsável é o retrato compreensivo destes encontros locais e globais com tudo o que eles possuem de saberes, deliberação, dominação e resistência, oralidade e experiência. Um olhar multissituado dos deslocamentos, tanto nos lugares de exclusão como de dominação. A construção de contranarrativas da Nação, que evocam e borram suas fronteiras totalizantes e homogeneizantes, pode ser um caminho frutífero, exercício que impede que estas comunidades imaginadas que são os Estado Nação cubram-se de identidades essencialistas e de um discurso homogêneo de progresso.

0 problema certamente não está nas vontades de cada indivíduo, mas sim nas violências estruturais, simbólicas e normalizadoras de nossas sociedades desiguais. Quando esta trialética conflui em uma mes- 
ma biografia, apesar dos esforços de cada indivíduo por se sobrepor a suas próprias circunstâncias, a luta parece perdida. E é então que a autodestruição e a autoimolação, como no escorpião, parece ser a única saída possível. Daí o dever de toda ciência de contribuir a gerar estas bases mínimas de respeito, através da "superação do olhar miserabilista e do cruzamento de olhares, até que as evidências das condicionantes estruturais saltem à vista" (BOURDIEU, 1995).

0 certo é que as capacidades de autodeterminação estão desigualmente distribuídas no tecido social, e sejam quais forem os recursos e capitais, a sua disponibilidade, acesso, aquisição e uso excedem sempre as nossas vontades individuais. A armadilha do neoliberalismo consiste em nos fazer pensar que "qualquer pessoa inteligente pode passar da miséria à abundância se trabalhar com determinação", nos recorda Bourgois. Práticas autodestrutivas que, longe de resistir e transformar o social, produzem uma avalanche de sofrimento que tende, em um contexto fortemente neoliberal, a ser individualizado, patologizado ou naturalizado pelos próprios atores e pelo discurso da mídia, das instituições públicas e da academia.

Em síntese, toda pesquisa social possui não somente um fundo profundamente político, como é também um chamado a favor da mudança de paradigma da questão social que rodeia a figura do excluído em nossa sociedade. 0 relato do cientista social, através do exercício reflexivo e polifônico, pode contribuir para desvelar as estruturas profundamente escondidas deste mundo social, assim como os mecanismos que tendem a assegurar a reprodução ou transformação, geralmente conflitiva, das condições sociais que lhe dão vida. Sem dúvida, em cada uma destas pesquisas está o reconhecimento do direito de homens e mulheres à afirmação de uma autonomia liberdade, e ao exercício de soberania sobre suas vidas e suas culturas.

Este é o desafio que enfrentamos hoje enquanto cientistas sociais: evocar e eliminar fronteiras totalizantes para abrir o olhar para o retrato e a compreensão das culturas do movimento, com tudo o que possuem de deliberação, dominação e resistência. Mais que tentar curas impossíveis ou reinserções inúteis, se trata de compreender o caráter irreversível de muitas das histórias que nascem em contextos estruturalmente excludentes e desiguais. Isto supõe, antes de mais nada, uma releitura do movimento e das rupturas não como transgressões e fracassos, mas como condições à existência destes sujeitos, um princípio de realidade. Uma mudança de perspectiva como o proposto supõe mudanças políticas profundas, como suspender esta necessidade social de normalizar e/ou patologizar seus membros “desviados”, excluídos ou marginalizados. Mas isto exige a aceitação e o respeito ao outro em suas diferenças e em seus desvarios. É esta aceitação e tolerância ao outro, sejam quais forem as suas disfunções, e sejam quais forem os benefícios que dele se possam extrair, que podem transformar a função da assistência ou da caridade - e não do castigo - na resposta que suavize e mitigue esta profunda ruptura do vínculo social. É uma exigência ética fundamental o reconhecimento ao direito de cada um a existir sem a exigência de transformar-se em algo distinto ao que são: sujeitos todos que a própria sociedade gestou.

Assim, a experiência das universidades chilenas nos ensina que a autonomia e a vocação pública não ocorrem sem esta relação com os saberes outros. Sem a rua, 
não há conhecimento crítico possível. Ser sinceros com as próprias interrogantes ao interior da comunidade acadêmica e universitária é a principal exigência para uma pesquisa social ética e criticamente responsável. Para as Ciências Sociais, o problema é especialmente complexo. Em um mundo letrado, a ruptura da autoridade intelectual diz respeito ao questionamento à superioridade do científıco na interpretação e compreensão da realidade social. Hoje, no Chile, são justamente as elites intelectuais dos povos originários, e em especial do Povo Mapuche, as que deslocam e questionam os saberes universitários. São eles também os que vão levantar a bandeira e a voz das reivindicações da Wallmapu (terras ancestrais).

Finalmente, o desafio das nossas universidades e das Ciências Sociais continua sendo o de contribuir e revelar as estruturas profundas de dominação neste mundo social, assim como os mecanismos que costumam garantir a sua reprodução e impedir a sua transformação.

\section{Referências}

AAA Código De Ética de La Asociación Antropológica Americana. Aprovado em junho de 1998. Tradução de Debbie Guerra e Juan Carlos Skewes, Valdivia, 1 de março de 2003. (1998)

ANDRADE, A. Trayectoria de las ciencias sociales en América Latina. Revista Mexicana de Ciencias Políticas y Sociales, v.36, n.141, p.89-105, 1990.

ATRIA, F. Sobre la universidad, lo público y la autonomía. In: COSTADOAT, J.; GARRIDO, J. M. (Orgs.). Ideas para la universidad. Santiago: Ediciones Universidad Alberto Hurtado, 2018.

BOUGOIS, P. En busca de respeto. Vendiendo crack en Harlem. Buenos Aires: Siglo XXI, 2014.

BOURDIEU, P. L'objectivation participante. Actes de la recherche en sciences sociales, $n .^{\circ} 150, \mathrm{p}$. 43-58, 2003.

BOURDIEU, P. ; Wacquant, L. Résponses. París: Seuil,1992.

BOURDIEU, P. La miseria del mundo. Buenos Aires: Fondo de Cultura Económica, 1999.

CALDERÓN, F. Situación, necesidades y perspectivas de las ciencias sociales en América Latina (pautas preliminares). Seminário José Agustín Silva Michelena: El estado actual de las ciencias sociales en América Latina, 1987, Caracas/Venezuela, 1987.

CONICYT. Ranking de universidades por Disciplina, Sub-área OECD, Ciencias Sociales. http://www. conicyt.cl/becasconicyt/postulantes/donde-estudiar-2/rankings-universidades/, 2017.

COSTADOAT, J. La universidad católica en perspectiva teológica. In: COSTADOAT, J.; GARRIDO, J. M. (Orgs.). Ideas para la universidad. Santiago: Ediciones Universidad Alberto Hurtado, 2018.

FLORIANI, D. Las Ciencias Sociales en América Latina: Lo permanente y transitorio, preguntas y desafíos de ayer y hoy. POLIS. Revista Latinoamericana, v.14, n41, p.127 - 146, 2015.

GARRETÓN, M. A. Los orígenes y desarrollo de la reforma en la Universidad Católica de Chile (1967-1973). In: COSTADOAT, J. ; GARRIDO, J. M. (Orgs.). Ideas para la universidad. Santiago: Ediciones Universidad Alberto Hurtado, 2018.

GARRIDO, J. M.; VALENTINA, P. Filosofía en la universidad. In: COSTADOAT, J. ; GARRIDO, J. M. (Orgs.). Ideas para la universidad. Santiago: Ediciones Universidad Alberto Hurtado, 2018.

GRACIARENA, J. Las ciencias sociales, la crítica intelectual y el Estado Tecnocrático. Aporte para una discusión del caso latinoamericano". In: SOLARI, A. E. Poder y desarrollo en América Latina. Estudios sociológicos en homenaje a José Medina Echavarría. México: Fondo de Cultura Económica, 1977, pp. 149-172.

HIRSCH, A. Ética de la ciencia y de la investigación cientifica. Ethos Educativo, n 30, 113-140, 2004. 
KROTZ, E. Las Antropologías latinoamericanas como segundas: situaciones y retos. GARCÍA, F. (Org.). II Congreso Ecuatoriano de Antropología y Arqueología. Balance de la última década: Aportes, Retos y nuevos temas, v. I, pp. 41-59, 2007.

LANDER, E. La colonialidad del saber: eurocentrismo y ciencias sociales. Perspectivas Latinoamericanas. Buenos Aires: CLACSO, 2000.

LARRAÍN, A.; Lira, E. Una lectura ética de la universidad contemporánea: la universidad como comunidad de investigación. In: COSTADOAT, J.; GARRIDO, J. M. (Orgs.). Ideas para la universidad. Santiago: Ediciones Universidad Alberto Hurtado, 2018.

MÁRQUEZ, F. De los invisibles y el derecho al anonimato. Apuntes para una ética en la investigación social. CONICYT, Protección de las personas en la investigación científica. Santiago, p.89 -94, 2013.

RICHARD, N. La invención y la herencia. Santiago: Universidad Arcis, Ediciones Lom,1995.

ROIG, A. (2007) Ética del poder y moralidad de la protesta: La moral latinoamericana de la emergencia http://ensayistas.org/filosofos/argentina/roig/ etica/etica10.html (consultado 24.01.2017).

Silva, E. La autonomía universitaria y los proyectos intelectuales determinados. In: COSTADOAT, J.; GARRIDO, J. M. (Orgs.). Ideas para la universidad. Santiago: Ediciones Universidad Alberto Hurtado, 2018.

STUVEN, A. M. La fundación de la UC: una respuesta educacional a la secularización. In: COSTADOAT, J.; GARRIDO, J. M. (Orgs.). Ideas para la universidad. Santiago: Ediciones Universidad Alberto Hurtado, 2018.

TAYLOR, D. El archivo y el repertorio. La memoria cultural performática en las Américas. Santiago: Ed. Universidad Alberto Hurtado: Colección Antropología, 2015. 
RESUMO

A história das Ciências Sociais na América Latina nos mostra que não podemos falar de ciência e Nação, pesquisa e compromisso, sem assumir a trama complexa das estruturas sociais, dos poderes e dos múltiplos saberes que subsistem nas nossas culturas. Para articular os saberes dos intelectuais às interrogantes de nossas sociedades, o desafio não é apenas compreender os problemas que estas estruturas e campos de interesses nos apontam, mas também os saberes outros, com os quais a ciência deve dialogar. A partir da análise do caso das universidades chilenas e das Ciências Sociais no país, se adverte sobre os riscos e as consequências do modelo neoliberal na construção social do conhecimento.

\section{PALAVRAS-CHAVE}

Universidade. Ética. Ciência. Conhecimento. Epistemologia.

\section{ABSTRACT}

The history of social sciences in Latin America shows us that we cannot talk about science and nation, research and commitment without assuming the complex web of social structures, powers and multiple knowledge underlying our cultures. When intellectuals express knowledge of questions about our societies, the challenge is not only understanding the problems that these structures and fields of interests do not pose but also other forms of knowledge that science must learn to discuss.

\section{KEYWORDS}

Ethics. Science. Knowledge. Epistemology. 